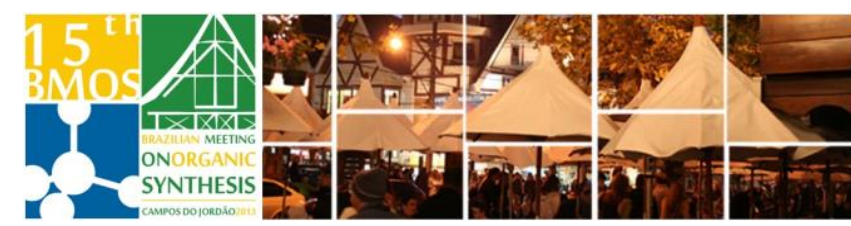

\title{
1,3-Dipolar Cycloaddition Reactions of meso-Tetra(2'- thienyl)porphyrins with a Nitrile Oxide
}

\author{
Patrícia B. Momo, Ricardo B. Ayres, Timothy J. Brocksom, Kleber T. de Oliveira* \\ Universidade Federal de São Carlos - UFSCar, Departamento de Química, 13565-905, São Carlos, SP, \\ Brazil. \\ *e-mail: kleber.oliveira@ufscar.br; www.lqbo.ufscar.br
}

Keywords: 1,3-dipolar cycloaddition, chlorins, bacteriochlorins

\section{INTRODUCTION}

Tetrathienylporphyrins have gained much interest recently due to their remarkable photophysical and electrochemical properties. ${ }^{1}$ Derivatives such as chlorins, isobacteriochlorins and bacteriochlorins, can be synthesized by reduction with diimide or para-toluenesulfonylhydrazide, as well as oxidation with $\mathrm{OsO}_{4}$, and Diels-Alder reactions and 1,3-dipolar cycloadditions, on the peripheral double bonds of the pyrrolic rings. ${ }^{2,3}$ Chlorins and bacteriochlorins have been used in several scientific areas, especially in medicine. We have now explored the 1,3-dipolar cycloaddition of 2,6-dichlorobenzonitrile oxide with tetra(2'-thienyl)porphyrins 1a-d (Scheme 1). We observed that tetra(2'-thienyl)porphyrins can react with the dipolarophile yielding chlorins and bacteriochlorins. These new compounds are candidates for use in photodynamic therapy (PDT) and solar cells studies.

\section{RESULTS AND DISCUSSION}

The 1,3-dipolar cycloaddition reactions of 2,6dichlorobenzonitrile oxide with tetra(2'thienyl)porphyrins and metallo-tetra(2'thienyl)porphyrins 1a-d yielded isoxazole-fused chlorins and bacteriochlorins (Scheme 1 and Table $1)$. The reactions were conducted with an excess of 2,6-dichlorobenzonitrile oxide at $80^{\circ} \mathrm{C}$ under argon atmosphere for 24-48 h, giving complex mixtures containing chlorins as the major product (Table 1), except for porphyrin 1c which gave chlorins and bacteriochlorins in similar yields of $13-15 \%$. After work-up and purification, the structures of the new compounds were confirmed by ${ }^{1} \mathrm{H}$ NMR, ${ }^{13} \mathrm{C} N M R$, HRMS and UV/Vis spectroscopies.

We are now performing studies on aggregation in solution, singlet oxygen generation and photobleaching in order to select some compounds for PDT studies.

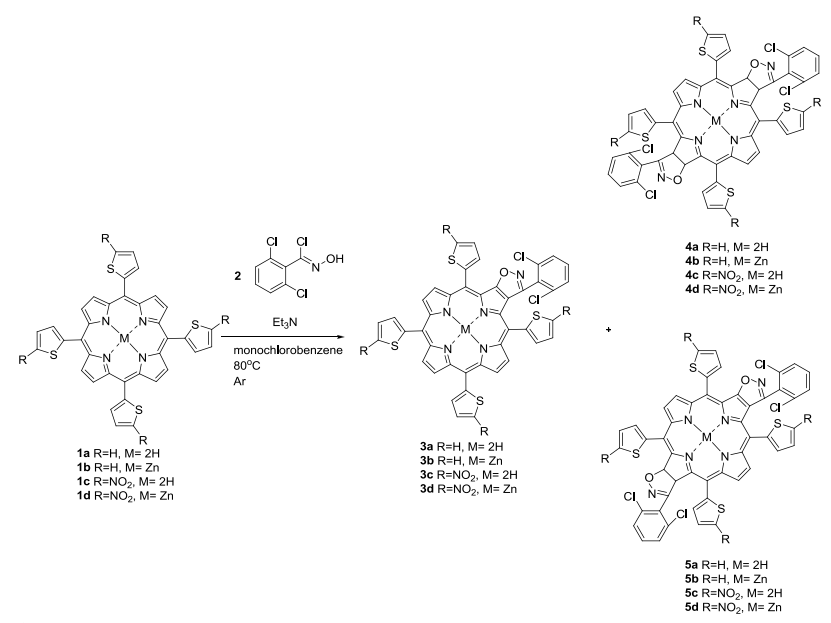

Scheme 1. Reaction of porphyrins 1a-d with 2,6dichlorobenzonitrile oxide.

Table 1. Product yields of porphyrins 1a-d with 2.6dichlorobenzonitrile oxide.

\begin{tabular}{cclll}
\hline Entry & Time $(\mathrm{h})$ & $\mathbf{3}(\%$ yield) & $\mathbf{4}(\%$ yield) & $\mathbf{5}(\%$ yield $)$ \\
\hline 1 & 24 & (a) 13 & (a) traces & (a) traces \\
2 & 24 & (c) 15 & (c) $13-$ & (c) 14 \\
3 & 48 & (b) 9 & (b) traces & (b) traces \\
4 & 48 & (d) 22 & (d) traces & (d) traces \\
\hline
\end{tabular}

\section{CONCLUSION}

meso-Tetra(2'thienyl)porphyins 1a-d participate in 1,3-dipolar cycloaddition reactions yielding new thienylchlorins and thienylbacteriochlorins.

\section{ACKNOWLEDGEMENTS}

The authors thank FAPESP (2011/13993-2, 2013/06532-4), CNPq and CAPES for financial support and fellowships.

\section{REFERENCES}

${ }^{1}$ Boyle, M. N.; Rochford, J.; Pryce, M. T. Coord. Chem. Rev. 2010, 254, 7.

${ }_{2}$ Xingang, L.; Yaqing, F.; Xiaofen, H.; Xianggao, L. Synthesis, 2005, 20, 3632.

${ }^{3} \mathrm{Li}, \mathrm{X}$.; Zhuang, J.; Li, Y.; Liu, H.; Wang, S.; Zhu, D. Tetrahedron Letters, 2005, 46, 1555. 